\title{
Effect of forskolin on the spontaneous maturation and cyclic AMP content of rat oocyte-cumulus complexes
}

\author{
Catherine Racowsky \\ Department of Zoology, Arizona State University, Tempe, Arizona 85287, U.S.A.
}

\begin{abstract}
Summary. Forskolin $(0-100 \mu \mathrm{M})$, a reversible stimulator of the catalytic subunit of adenylate cyclase, induced dose-response increases in the \% germinal vesicle (GV) $\left(\mathrm{ID}_{50}=2.68 \mu \mathrm{M}\right.$, where $\mathrm{ID}_{50}$ is the dose of forskolin which maintained the meiotic arrest at the germinal vesicle stage, determined cytogenetically, of $50 \%$ cultured oocytes), and the cAMP content (determined by RIA) of cumulus-enclosed oocytes and cumulus masses. A significant positive correlation was established between the amount of CAMP within the cumulus mass and that in the corresponding enclosed oocyte $(r=0.78)$. In contrast, neither the $\% \mathrm{GV}$ nor the cAMP content of cumulus-free oocytes was affected by the drug. The arresting action of forskolin upon cumulus-enclosed oocytes was dependent upon the presence of adherent cumulus cells, and was transient and fully reversible. The gradual decrease in the $\% \mathrm{GV}$ of cumulusenclosed oocytes cultured from 4 to $12 \mathrm{~h}$ in $25 \mu \mathrm{M}$-forskolin $(84,54$ and $22 \% \mathrm{GV}$ at 4,8 and $12 \mathrm{~h}$, respectively) was accompanied by a drastic fall in intra-oocyte cAMP at $8 \mathrm{~h}$ $(41.2 \pm 2.5$ and $1.1 \pm 0.6 \mathrm{fmol} /$ oocyte at 4 and $8 \mathrm{~h}$, respectively), while the cumulus cell cAMP content remained constant $(135.3 \pm 14.7$ and $145.9 \pm 28.7 \mathrm{fmol} /$ cumulus at 4 and $8 \mathrm{~h}$, respectively). Moreover, heterologous metabolic coupling, assessed by determination of the fraction of radiolabelled uridine marker that was transferred from the cumulus mass to the oocyte, significantly decreased. These results show that cumulus cell cAMP is transferred to the rat oocyte where it appears to play a pivotal role in the regulation of meiosis and that the rat oolemma does not appear to possess active catalytic subunits of adenylate cyclase in an amount adequate to stimulate measurably cAMP synthesis.
\end{abstract}

\section{Introduction}

Considerable attention has been focussed recently upon the hypothesis, originally advanced by Dekel \& Beers (1978, 1980), that cAMP and cumulus-oocyte intercellular metabolic coupling each have central roles in the regulation of mammalian meiotic maturation. This hypothesis proposes that cAMP, derived from the cumulus cells and transferred to the ooplasm via intercellular coupling, is the informational molecule which regulates oocyte maturation. It is postulated that a minimum threshold level of the nucleotide is required to maintain meiotic arrest; disruption of functional metabolic coupling between the oocyte and its cumulus cells results in a reduction of intra-oocyte cAMP below the threshold level and in a resumption of meiosis. Maintenance of the integrity of functional coupling between the immature oocyte and cumulus cell, and the inability of the oocyte to synthesize cAMP in an amount sufficient to maintain the concentration of nucleotide above the threshold level, are therefore implicit in the maintenance of meiotic arrest.

Evidence favouring a regulatory function for cAMP is derived from the observations that a decrease in oocyte cAMP preceded maturation in the mouse (Vivarelli, Conti, De Felici \& 
Siracusa, 1983; Schultz, Montgomery \& Belanoff, 1983a). In addition, maturation is prevented by the cyclic nucleotide derivative, $\mathrm{N}^{6}, \mathrm{O}^{2}$-dibutyryl adenosine $3^{\prime}, 5^{\prime}$-cyclic monophosphoric acid (dbcAMP) (Cho, Stern \& Biggers, 1974; Magnusson \& Hillensjö, 1977; Dekel \& Beers, 1978, 1980; Rice \& McGaughey, 1981 ; Vivarelli et al., 1983; Racowsky, 1983), by phosphodiesterase inhibitors (Cho et al., 1974; Magnusson \& Hillensjö, 1977; Dekel, Lawrence, Gilula \& Beers, 1981), and by choleratoxin, an irreversible stimulator of the regulatory subunit of adenylate cyclase (Dekel \& Beers, 1978). Since choleratoxin did not inhibit the maturation of cumulus-free (denuded) rat oocytes, it was concluded that the oolemma may not possess an active adenylate cyclase system (Dekel \& Beers, 1980). Intercellular coupling between oocytes and cumulus cells has been documented by several morphological (Szöllösi, 1975; Anderson \& Albertini, 1976) and biochemical (Gilula, Epstein \& Beers, 1978; Heller \& Schultz, 1980; Moor, Smith \& Dawson, 1980) studies.

Results of additional biochemical studies with oocytes of mouse (Eppig, 1982; Schultz, Montgomery, Ward-Bailey \& Eppig, 1983b), sheep (Moor \& Heslop, 1981) and pig (C. Racowsky, unpublished), however, may argue against the concepts that a reduction in intra-oocyte cAMP is a prerequisite for the resumption of meiosis and that cAMP is transferred from the functionally coupled cumulus cell into the oocyte to maintain meiotic arrest. Under conditions which stimulated cAMP synthesis in mouse cumulus cells, no increase in nucleotide concentration was observed within the enclosed oocyte, despite the maintenance of intercellular metabolic coupling (Schultz et al., 1983b). No decrease in the content of intra-oocyte cAMP was observed before the reinitiation of meiosis when intact ovine follicles were exposed to gonadotrophins in vitro (Moor \& Heslop, 1981) or when liberated intact pig oocytes were matured in culture (C. Racowsky, unpublished). These recent findings clearly indicate that further studies are required to test the hypothesis of Dekel \& Beers (1980). The experiments reported in this paper provide such a study using the liberated rat oocyte in the bioassay and the diterpene, forskolin, to stimulate adenylate cyclase activity. Forskolin was selected because this drug very rapidly and reversibly activates the catalytic subunit of adenylate cyclase (Seamon, Padgett \& Daly, 1981; Seamon \& Daly, 1981), thus permitting concise manipulation of the cAMP content of the cells. The hypotheses tested were that (1) elevation of cumulus cell cAMP results in an increase in rat oocyte cAMP and in a concomitant increase in the maintenance of meiotic arrest when heterologous metabolic coupling is maintained and (2) the rat oolemma does not possess catalytic subunits of adenylate cyclase in a quantity adequate to stimulate sufficient cAMP accumulation to maintain meiotic arrest.

\section{Materials and Methods}

Collection of oocytes. Oocytes were collected from sexually immature Long-Evans Hooded rats (28 days old) $48 \mathrm{~h}$ after subcutaneous injection of 6 i.u. PMSG (Sigma, St Louis, MO). The rats were asphyxiated with carbon dioxide, the ovaries were removed immediately, and each pair of ovaries was placed in a sterile dish (Falcon Plastics; No. 1008) containing BMOC-3 medium (Brinster 1971), modified as described by McGaughey (1977) (BMOC-2A). The largest follicles ( $>0.8 \mathrm{~mm}$ diam.) were punctured with a sterile 26-gauge needle into BMOC-2A medium under a dissecting microscope. Only those oocytes with an intact, tightly adherent mass of cumulus cells were selected for subsequent experiments (10-15 oocytes/ovary). Cumulus-free (denuded) oocytes were obtained by mechanically removing cumulus cells from cumulus-enclosed oocytes with a small-bore pipette (Hillensjö, Hamberger \& Ahren, 1975; McGaughey \& Van Blerkom, 1977). All oocytes were washed three times in the appropriate medium before culture. The average times between release from the ovary, collection and preparation for culture, and the start of culture of cumulus-enclosed and denuded oocytes were $4.3 \pm 0.2(n=24)$ and $5.5 \pm 0.3(n=24) \mathrm{min}$, respectively. In experiments in which the response of cumulus-enclosed and denuded oocytes was examined, the former oocytes were obtained from one ovary and the latter from the contralateral ovary. Generally 8 rats were killed for each experiment. 
Culture procedures. The oocytes were cultured for up to $12 \mathrm{~h}$ in wells of Lab-Tek chamber slides (No. 4838) in $0.2 \mathrm{ml}$ medium under a humidified atmosphere of $5 \% \mathrm{CO}_{2}, 5 \% \mathrm{O}_{2}$ and $90 \% \mathrm{~N}_{2}$ in a desiccator at $37^{\circ} \mathrm{C}$. Cultures were maintained in the complex medium described by Tsafriri \& Channing (1975) except that Hanks' salts were substituted for Earles' salts, since preliminary experiments had shown that rat oocytes will not mature spontaneously in medium supplemented with Earles' salts. The medium (TC) consisted of Medium 199 with Hanks' salts and 25 mM-Hepes buffer (Gibco) supplemented with $15 \%$ pig serum (Gibco), 1 mM-glutamine, 2.5 mM-lactate, 0.03 mM-pyruvate, $12.5 \mathrm{mU}$ insulin $/ \mathrm{ml}$ and $50 \mu \mathrm{g}$ gentamicin $/ \mathrm{ml}$. Stock solutions of insulin, gentamicin and sodium pyruvate were prepared in Medium 199, divided into appropriate aliquots and stored frozen at $-20^{\circ} \mathrm{C}$. The serum was likewise stored in suitable volumes. Media were prepared the evening before an experiment. A stock solution of forskolin ( $10 \mathrm{~mm}$; Calbiochem-Behring, La Jolla, CA) was prepared in $95 \%$ ethanol, and media containing forskolin were prepared by the aseptic addition of an appropriate volume of the stock solution. The concentration of ethanol never exceeded $10 \mu \mathrm{l} / \mathrm{ml}$, and an equivalent volume of ethanol was added to media which did not contain forskolin. Groups of 10-15 oocytes (those obtained from one ovary) were cultured in each well. Within an experiment one replicate was normally provided for each treatment and each experiment was repeated at least 3 times. After culture, oocytes were processed for cAMP radioimmunoassay or metabolic coupling determinations, or were prepared for cytogenetic analysis of meiotic stage.

Determination of meiotic stage. Oocytes were denuded, air-dried as described previously (McGaughey \& Polge, 1971), and stained with Wright's stain in 2.9\% (w/v) glycerol and 97.1\% methanol (Rice \& McGaughey, 1981). Oocyte maturation was scored cytogenetically (McGaughey, 1977), and classified as described previously (McGaughey \& Polge, 1971; Rice \& McGaughey, 1981).

Measurement of metabolic coupling. The assay system of Moor et al. (1980) for metabolic coupling was used in which denuded ovine oocytes took up substantially less $\left[{ }^{3} \mathrm{H}\right]$ uridine marker than did cumulus-enclosed oocytes when heterologous junctional complexes were present, as assessed by electron microscopy. Cumulus-enclosed or denuded oocytes were incubated for $1 \mathrm{~h}$ in Medium TC, with or without forskolin and containing $\left[5,6^{-3} \mathrm{H}\right]$ uridine (sp. act. $38 \cdot 4 \mathrm{Ci} / \mathrm{mmol}$ : New England Nuclear, Boston, MA) at a concentration of $8 \mu \mathrm{M}$. Preliminary experiments showed a concentration-dependency for uptake of marker into cumulus-enclosed oocytes; while the uptake was directly proportional to the concentration of uridine over the range 1-8 $\mu \mathrm{M}$, there was a tendency to plateau at higher concentrations $(8-60 \mu \mathrm{M})$ (data not shown). The $8 \mu \mathrm{M}$ concentration of uridine therefore ensured that the uptake and/or metabolism of uridine took place at near-maximal rates. After incubation, oocytes were washed 4 times in BMOC-3 medium and subsequently transferred to $5 \mu \mathrm{BMOC}-3$ on a piece of glass coverslip $\left(11 \mathrm{~mm}^{2}\right)$. Cumulus cells were removed mechanically and the denuded oocytes were removed, washed and transferred into a $5 \mu l$ drop of $0.5 \%$ sodium dodecylsulphate (SDS) in glass distilled water ( $w / v)$ (Pharmacia) on an additional piece of coverslip. The cumulus cells were likewise lysed in $5 \mu 10.5 \%$ SDS, and the oocyte and cumulus cell samples were counted separately in a Beckman Liquid Scintillation counter. Correction for quenching used the external standard method (Wang, Willis \& Loveland, 1975), and uptake was expressed as pmol marker per oocyte or cumulus mass. During the first hour of culture in Medium TC containing $8 \mu \mathrm{M}$-uridine, denuded oocytes took up approximately $15 \%$ of the total amount of marker taken up by cumulus-enclosed oocytes $(3 \cdot 3 \pm 0 \cdot 3$ and $19 \cdot 0 \pm 2 \cdot 7$ pmol/oocyte, respectively; $n=8$ for both).

Determination of cyclic AMP by radioimmunoassay. Cyclic AMP was measured by radioimmunoassay using RIA kits (New England Nuclear). The labelled antigen was a succinyl tyrosine-[ $\left.{ }^{125} I\right]-$ methyl ester derivative of cAMP. Separation of bound from free antigen was achieved by the use of a primary and secondary antibody complex. The primary antibody was prepared in rabbits against a succinyl cAMP-albumin conjugate, while the second antibody was prepared in sheep against 
rabbit globulin. The cross-reactivity of the antiserum was $<0.00008$ with cGMP, AMP, ADP and ATP. After culture, groups of 5-10 cumulus-enclosed or denuded oocytes were transferred to 2-5 $\mu 1$ drops of BMOC-3 medium containing $0.1 \%$ hyaluronidase $(\mathrm{w} / \mathrm{v}$; Sigma) and $1 \mathrm{mM}$-isobutylmethylxanthine (MIX) on the end of a coverslip strip approximately $2 \mathrm{~mm}$ wide. This concentration of MIX was used since $1 \mathrm{mM}$ has been shown to inhibit phosphodiesterase activity maximally in intact cells (including Xenopus oocytes; Mulner, Cartaud \& Ozon, 1980). Cumulus cells were removed mechanically and the denuded oocytes were immediately transferred to $10 \mu 10.5 \%$ SDS (w/v in glass-distilled water) in a $200 \mu \mathrm{l}$ microcap (Bolab Inc.). Oocytes were transferred in a very small volume of cumulus-free medium at $\times 250$ magnification; no cumulus cells were seen in any oocyte sample. The coverslip strip with cumulus cells was transferred to a microcap and $10 \mu 10.5 \%$ SDS were carefully run down the glass strip to wash the cells into the bottom of the microcap. After $\sim 5$ min, lysis was complete and the samples were capped and stored at $-80^{\circ} \mathrm{C}$. Before extraction with $100 \mu 16 \%$ trichloroacetic acid (TCA) at $4^{\circ} \mathrm{C}$, samples were thawed, vortexed for $1 \mathrm{~min}$ and $10 \mu 1$ BSA $(10 \mathrm{mg} / \mathrm{ml}$ in glass-distilled water, Sigma) were added to each microcap to act as carrier protein. Extracted samples were centrifuged at $2000 \mathrm{~g}$ for $15 \mathrm{~min}$ at $4^{\circ} \mathrm{C}$, the supernatants were removed and dried down under a stream of air in a water-bath at $75^{\circ} \mathrm{C}$. TCA extracts were diluted when necessary and were assayed after acetylation (Harper \& Brooker, 1975); samples were counted in a gamma counter (Packard Model No. 578). The assay had a sensitivity of $2.5 \mathrm{fmol}$ cAMP but only the linear portion of the standard curve was used (5.0-250 fmol). The inter- and intra-assay coefficients of variation, derived from 8 assays were, respectively, $7.9 \%$ and $4 \cdot 1 \%$ as calculated from quality control samples run with each assay. The amount of cAMP was linearly related to the number (5-20) of oocytes $(r=0.96)$ and cumulus masses $(r=0.93)$ assayed after culture in medium containing $0 \cdot 195 \mu \mathrm{M}$-forskolin. Extracts of blank samples composed of an equal volume of BMOC-3 medium supplemented with $100 \mu \mathrm{g}$ BSA and $1 \mathrm{mM}-\mathrm{MIX}$ in $10 \mu \mathrm{l} 0.5 \%$ SDS contained $10 \mathrm{fmol}$ cAMP. This blank value was subtracted from all determinations. The cAMP content of oocytes previously cultured within their cumulus masses was not distorted by cumulus cell contamination since there was no significant difference between the amount of cAMP in unwashed $(18.1 \pm 3.9 \mathrm{fmol} ; n=4)$ and washed $(20.1 \pm 3.5 \mathrm{fmol} ; n=4)$ oocytes after denudation following culture for $4 \mathrm{~h}$ in medium containing $12.5 \mu \mathrm{M}$-forskolin. No allowance was made for extraction losses of 5-10\% cAMP.

Statistical analyses. The cytogenetic data were analysed by Duncan multiple range tests using the SPSS computer program (Duncan, 1955; Nie, Hull, Jenkins, Steinbrenner \& Brent, 1975; McGaughey, 1978) after transformation to angles as previously described (McGaughey, 1978). Significant differences amongst experimental and control groups were approximated at $\alpha=0.05$. Group means and their $95 \%$ confidence intervals were transformed back to percentages for tabulation.

Best-fit curves of the maturation data obtained from the dose-response studies were established using least squares analysis and polynomial regression. These analyses were undertaken using the Curfit Program of Warme (1980) run on an Apple II computer.

The metabolic coupling and cAMP data were analysed by Duncan multiple range tests or by Student's paired $t$ test, with $P<0.05$ considered statistically significant.

\section{Results}

Series 1

The effects of forskolin $(0-100 \mu \mathrm{M})$ upon the meiotic maturation and cAMP content of oocytes after $4 \mathrm{~h}$ of culture were first investigated. The meiotic arrest $(\% \mathrm{GV})$ of cumulus-enclosed oocytes was dependent upon the concentration of forskolin in a dose-dependent manner ID $_{50}=2.68 \mu \mathrm{M}$; where $\mathrm{ID}_{50}$ is the dose of forskolin which maintained the meiotic arrest of $50 \%$ cultured oocytes), the minimum dose of forskolin necessary to facilitate maximal $\% \mathrm{GV}$ being $35 \mu \mathrm{M}$. The meiotic 


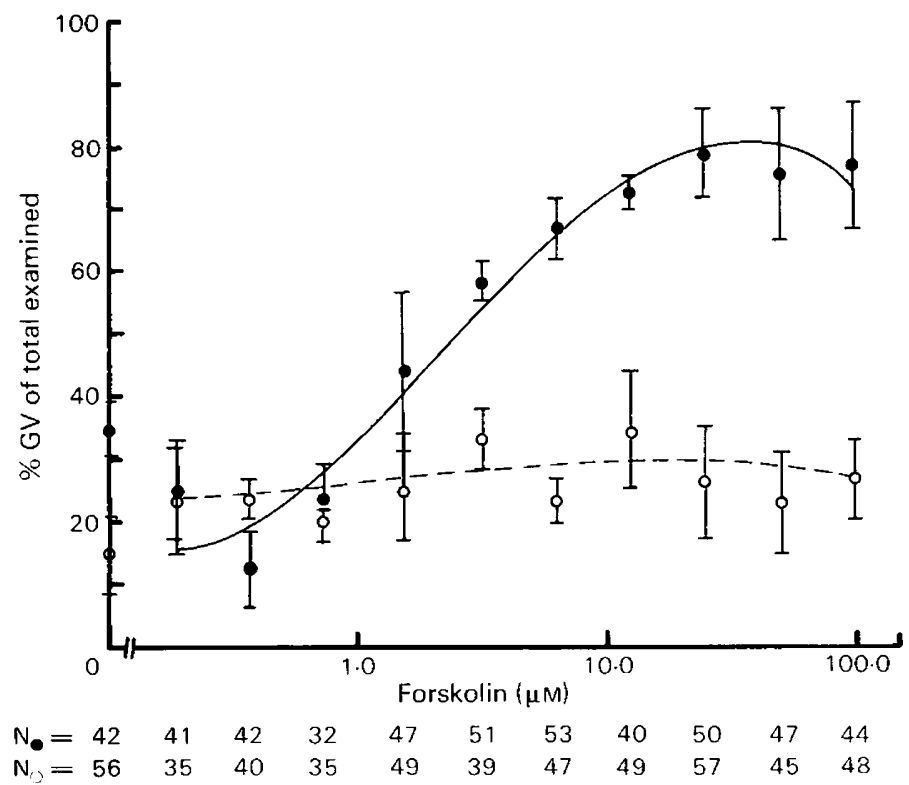

Text-fig. 1. Forskolin action upon the spontaneous maturation of rat oocytes. Cumulusenclosed (O) and denuded (O) oocytes were cultured for $4 \mathrm{~h}$ in the presence of various concentrations of forskolin. Meiotic arrest $(\% \mathrm{GV})$ was determined cytogenetically. Each point represents the mean \pm s.e.m. of 4 replicate cultures. The regression lines are the lowest-order polynomials required to fit the data.

arrest of denuded oocytes, however, was unaffected by the diterpene over the same concentration range (Text-fig. 1). It is unlikely that the drug exerted a transient arrest on denuded oocytes because there was no significant difference in the $\% \mathrm{GV}$ of denuded oocytes cultured for only $2 \mathrm{~h}$ in medium containing $50 \mu \mathrm{M}$-forskolin as compared with control medium $(63 \cdot 1 \pm 7 \cdot 9$ and $69 \cdot 1 \pm 11 \cdot 6$, total no. of oocytes examined $=59$ and 64 , respectively; $n=4$ in both cases). Furthermore, whilst there was a dose-dependent relationship for the proportion of maturing cumulus-enclosed oocytes that had progressed only to diakinesis $\left(\mathrm{ID}_{50}=7.5 \mu \mathrm{M}\right.$ ), no such relationship existed with denuded oocytes.

The cAMP content of cumulus cells and oocytes cultured for $4 \mathrm{~h}$ in various concentrations of forskolin is shown in Text-fig. 2. Dose dependencies were revealed between the amount of cyclic nucleotide within the intact oocyte or the cumulus mass and the dose of drug in the medium. The cAMP content of oocytes enclosed within the cumulus masses was higher than that of denuded oocytes at each concentration of forskolin tested $(P<0.02$ at $3.195 \mu \mathrm{M}$ and $P<0.001$ at $12.5 \mu \mathrm{M}$ and $50.0 \mu \mathrm{M}$, paired $t$ test). Furthermore, the cAMP content of cumulus-enclosed oocytes cultured in all doses of forskolin was higher than that of intact oocytes cultured in control medium $(0.782 \mu \mathrm{M}$, $P<0.02 ; 3.125 \mu \mathrm{M}, P<0.01 ; 12.5 \mu \mathrm{M}, P<0.001 ; 50 \mu \mathrm{M}, P<0.001$ : paired $t$ test). Forskolin did not significantly increase the cAMP content of denuded oocytes, compared with controls. A significant positive correlation was established between the amount of cAMP within groups of cumulus masses and that in the corresponding groups of enclosed oocytes $(y=4 \cdot 33 x+65 \cdot 12$; $r=0.78, P<0.001$; where $x$ is fmol cAMP/oocyte and $y$ is fmol cAMP/cumulus mass).

\section{Series 2}

The arresting action of forskolin upon the meiosis of oocytes was dependent upon the presence of cumulus cells adherent to the oocyte; when denuded oocytes were co-cultured with free cumulus cells, meiotic arrest was not affected significantly by $25.0 \mu \mathrm{M}$-forskolin, a concentration which 


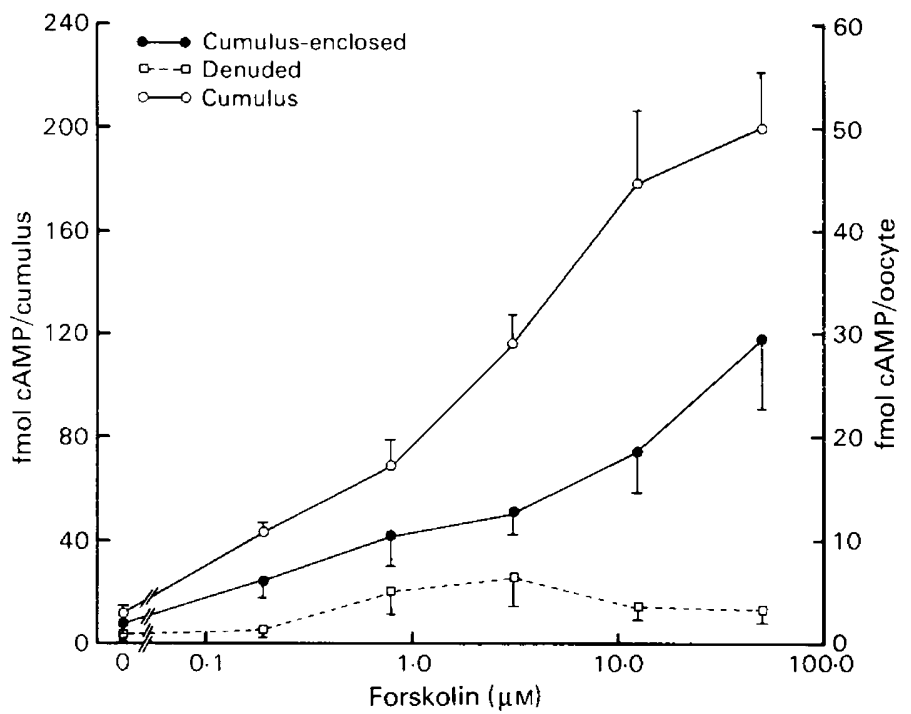

Text-fig. 2. The effect of forskolin on the cAMP content of denuded oocytes, cumulusenclosed oocytes and cumulus masses of the rat. Each value represents the mean \pm s.e.m. of 7 replicates (5-10 oocytes or cumulus masses/replicate). The same group of oocyte-cumulus complexes was used for the separate determinations of cAMP within the oocyte and cumulus mass.

Table 1. The dependence of forskolin-maintained meiotic arrest upon the presence of adherent cumulus cells during culture of rat oocytes for $4 \mathrm{~h}$

\begin{tabular}{lccc}
\hline \multicolumn{1}{c}{ Type of oocyte } & $\begin{array}{c}\text { Forskolin } \\
(\mu \mathrm{M})\end{array}$ & $\begin{array}{c}\text { No. of } \\
\text { cocytes }\end{array}$ & $\begin{array}{c}\text { Mean \% oocytes at } \\
\text { GV stage* }\end{array}$ \\
\hline Cumulus-enclosed & 25 & 84 & $72 \cdot 5^{\mathrm{a}}(65 \cdot 8-78 \cdot 8)$ \\
Denuded & 25 & 69 & $39 \cdot 9^{\mathrm{b}}(35 \cdot 8-43 \cdot 2)$ \\
Denuded + cumulus cells & 25 & 94 & $46 \cdot 9^{\mathrm{b}}(37 \cdot 7-56 \cdot 2)$ \\
\hline
\end{tabular}

* Mean (with $95 \%$ confidence limits) for 6 replicates.

Groups with different superscripts are significantly different, $\alpha=0.05$.

Table 2. The reversibility of forskolin action upon maintenance of meiotic arrest of cumulus-enclosed rat oocytes

\begin{tabular}{|c|c|c|c|c|}
\hline \multirow[b]{2}{*}{ Medium supplement } & \multirow[b]{2}{*}{$\begin{array}{l}\text { No. of } \\
\text { oocytes }\end{array}$} & \multirow[b]{2}{*}{$\begin{array}{l}\text { Total culture } \\
\text { time (h) }\end{array}$} & \multicolumn{2}{|c|}{ Mean $\%$ of oocytes which matured } \\
\hline & & & $\begin{array}{c}\text { Category I } \dagger \\
\text { (GV) }\end{array}$ & $\begin{array}{c}\text { Category II } \ddagger \\
\text { (diakinesis) }\end{array}$ \\
\hline None & 27 & 2 & $19 \cdot 7^{\mathrm{a}}(3 \cdot 1-79 \cdot 1)$ & $10 \cdot 0^{\mathrm{A}}(0 \cdot 3-31 \cdot 1)$ \\
\hline $25 \cdot 0 \mu \mathrm{M}$-forskolin & 35 & 2 & $80.8^{\mathrm{b}}(41 \cdot 5-99 \cdot 8)$ & $10 \cdot 6^{\mathrm{A}}(1 \cdot 1-48 \cdot 3)$ \\
\hline None & 29 & 4 & $8 \cdot 5^{\mathrm{a}}(6 \cdot 2-55 \cdot 8)$ & $3.5^{A}(1.9-5.5)$ \\
\hline $25.0 \mu \mathrm{M}$-forskolin & 26 & 4 & $66 \cdot 0^{\mathrm{b}}(40 \cdot 7-87 \cdot 1)$ & $16^{-9}(0-56 \cdot 1)$ \\
\hline $\begin{array}{l}25 \cdot 0 \mu \mathrm{M} \text {-forskolin }(2 \mathrm{~h}) \\
\text { then none }(2 \mathrm{~h})\end{array}$ & 36 & 4 & $27 \cdot 5^{\mathrm{a}}(6 \cdot 6-55 \cdot 9)$ & $49 \cdot 7^{\mathrm{B}}(37 \cdot 2-62 \cdot 1)$ \\
\hline
\end{tabular}

Values are means with $95 \%$ confidence limits.

$\dagger \%$ of oocytes derived from 3 replicates.

$\$ \%$ of oocytes that matured.

Groups with different superscripts are significantly different, $\alpha=0.05$. 
significantly inhibited the maturation of cumulus-enclosed oocytes (Table 1). Further analysis of the arresting action of forskolin revealed that the action was reversible, since intact oocytes cultured for $2 \mathrm{~h}$ in medium containing $25.0 \mu \mathrm{M}$-forskolin matured at control levels after being transferred to unsupplemented medium for an additional $2 \mathrm{~h}$ (Category I, Table 2). Nevertheless, significantly more maturing oocytes that had previously been exposed to forskolin were at diakinesis than were control oocytes cultured for $2 \mathrm{~h}$ (Category II, Table 2).

\section{Series 3}

The arresting action of forskolin was transient, since the proportion of intact oocytes maintained at the germinal vesicle stage was dependent upon the time of exposure to forskolin (25.0 $\mu \mathrm{M}$ ), and only $24 \%$ remained arrested after culture for $12 \mathrm{~h}$ (Table 3 ). This transient arresting action of the drug was accompanied by a marked time-dependent decrease in the cAMP content of cumulus cells and the enclosed oocytes, the most marked decreases occurring in the cumulus cells between 2 and $4 \mathrm{~h}$ and in the oocyte between 4 and $8 \mathrm{~h}$ of culture (Table 4). From 4 to $8 \mathrm{~h}$, the intra-

Table 3. The effect of forskolin on the meiotic progression and heterologous metabolic coupling of rat oocytes

\begin{tabular}{|c|c|c|c|c|c|c|}
\hline \multirow[b]{2}{*}{$\begin{array}{l}\text { Culture } \\
\text { time (h) }\end{array}$} & \multirow[b]{2}{*}{ Forskolin } & \multicolumn{2}{|c|}{ Meiotic maturation } & \multicolumn{3}{|c|}{ Metabolic coupling } \\
\hline & & $\begin{array}{c}\text { No. of } \\
\text { oocytes }\end{array}$ & $\% \mathrm{GV}$ & $\begin{array}{l}\text { pmol/ } \\
\text { oocyte† }\end{array}$ & $\begin{array}{c}\text { pmol } / \\
\text { cumulus mass } \dagger\end{array}$ & $\begin{array}{c}\text { Transfer } \\
\text { ratio }\end{array}$ \\
\hline 2 & $\overrightarrow{+}$ & $\begin{array}{l}38 \\
41\end{array}$ & $\begin{array}{l}41 \cdot 2(5 \cdot 1-82 \cdot 5) \\
93 \cdot 3(57 \cdot 2-95 \cdot 3)\end{array}$ & $\begin{array}{l}26.5 \pm 0.8 \\
11.4 \pm 1.5\end{array}$ & $\begin{array}{r}161.7 \pm 8.9 \\
51.1 \pm 8.1\end{array}$ & $\begin{array}{l}0.17 \pm 0.01 \\
0.23 \pm 0.01\end{array}$ \\
\hline 4 & $\begin{array}{l}- \\
+\end{array}$ & $\begin{array}{l}48 \\
48\end{array}$ & $\begin{array}{l}13 \cdot 5(2 \cdot 2-56 \cdot 6) \\
84 \cdot 5(38 \cdot 5-98 \cdot 6)\end{array}$ & $\begin{array}{r}38.9 \pm 5.8 \\
8.0 \pm 1.0\end{array}$ & $\begin{array}{c}230.9 \pm 25.5 \\
45.4 \pm 6.8\end{array}$ & $\begin{array}{l}0.17 \pm 0.02 \\
0.18 \pm 0.01\end{array}$ \\
\hline 8 & $\begin{array}{l}- \\
+\end{array}$ & $\begin{array}{l}35 \\
42\end{array}$ & $\begin{array}{c}8 \cdot 3(5 \cdot 4-51 \cdot 5) \\
54 \cdot 5(24 \cdot 0-83 \cdot 4)\end{array}$ & $\begin{array}{l}29 \cdot 6 \pm 2 \cdot 0 \\
12.2 \pm 2 \cdot 7\end{array}$ & $\begin{array}{l}240 \cdot 5 \pm 37 \cdot 4 \\
109 \cdot 9 \pm 26 \cdot 0\end{array}$ & $\begin{array}{l}0.13 \pm 0.02 \\
0.12 \pm 0.02\end{array}$ \\
\hline 12 & $\overline{+}$ & $\begin{array}{l}31 \\
43\end{array}$ & $\begin{array}{c}6 \cdot 8(6.6-20 \cdot 0) \\
24 \cdot 1(15 \cdot 4-33.9)\end{array}$ & $\begin{array}{l}22.8 \pm 2.7 \\
23.8 \pm 3.3\end{array}$ & $\begin{array}{l}254.9 \pm 15.4 \\
233.7 \pm 14.7\end{array}$ & $\begin{array}{l}0.09 \pm 0.01 \\
0.10 \pm 0.01\end{array}$ \\
\hline
\end{tabular}

Cumulus-enclosed oocytes were cultured for up to $12 \mathrm{~h}$ in the presence or absence of $25.0 \mu \mathrm{M}$-forskolin and were scored for \% GV (4 replicates) or incubated for the final hour of culture in the same medium but with uridine for determination of heterologous metabolic coupling (3 replicates, 5-10 oocytes/replicate). The transfer ratio represents the proportion of radiolabelled uridine marker within a group of oocytes of that present in the corresponding group of cumulus masses.

* Total number of oocytes scored for meiotic maturation.

$\dagger$ pmol uridine marker taken up.

Table 4. The effect of duration of culture upon the cAMP content of cumulus-enclosed rat oocytes cultured in the presence of $25 \mu \mathrm{M}$-forskolin

\begin{tabular}{ccc}
\hline $\begin{array}{c}\text { Culture } \\
\text { time (h) }\end{array}$ & $\begin{array}{c}\text { fmol cAMP/ } \\
\text { cumulus mass }\end{array}$ & $\begin{array}{c}\text { fmol cAMP/ } \\
\text { oocyte }\end{array}$ \\
\hline 2 & $312 \cdot 3 \pm 85 \cdot 2^{\mathrm{a}}$ & $27 \cdot 5 \pm 10 \cdot 1^{\mathrm{A}}$ \\
4 & $135 \cdot 3 \pm 14 \cdot 7^{\mathrm{b}}$ & $41 \cdot 2 \pm 2 \cdot 5^{\mathrm{A}}$ \\
8 & $145.9 \pm 28 \cdot 7^{\mathrm{b}}$ & $1 \cdot 1 \pm 0.6^{\mathrm{B}}$ \\
12 & $62.5 \pm 8 \cdot 8^{\mathrm{c}}$ & $0.5 \pm 0 \cdot 1^{\mathrm{B}}$ \\
\hline
\end{tabular}

Each value represents the mean \pm s.e.m. of 4 replicates (5-10 oocytes or cumulus masses/replicate). The same group of oocyte-cumulus complexes was used for the separate determination of CAMP within the intact oocyte and cumulus mass.

Groups with different superscripts are significantly different $(\alpha=0.05)$, when comparing the cAMP content of cumulus masses $(a, b, c)$ or oocytes $(A, B, C)$ with each other. 
oocyte cAMP level had decreased significantly from $41 \cdot 2 \pm 2.5$ to $1.1 \pm 0.6 \mathrm{fmol} /$ oocyte, while the content of cAMP in cumulus cells remained constant $(135 \cdot \overline{3} \pm 14.7$ and $145.9 \pm 28.7 \mathrm{fmol} /$ cumulus at 4 and $8 \mathrm{~h}$, respectively). Heterologous metabolic coupling significantly declined with culture time in the absence $(t=-4.04, P<0.01$, paired $t$ test $)$ and presence $(t=-6.89, P<0.001$, paired $t$ test) of forskolin (Table 3), but there was no significant effect of forskolin on this metabolism $(t=$ $-1 \cdot 32, P>0.05$, paired $t$ test).

\section{Discussion}

The results of this study strongly suggest that cumulus cell cAMP is transferred to the rat oocyte where it plays a role in the maintenance of meiotic arrest and that the rat oolemma lacks sufficient functional catalytic subunits of adenylate cyclase to stimulate adequate intra-oocyte cAMP to maintain meiotic arrest. These findings are therefore consistent with the hypothesis of Dekel \& Beers $(1978,1980)$ for the regulation of mammalian meiotic maturation.

The observations that forskolin failed to maintain the meiotic arrest (Text-fig. 1) or to elevate the cAMP content (Text-fig. 2) of denuded rat oocytes contrast those reported for denuded mouse (Schultz et al., 1983a; Urner, Herrmann, Baulieu \& Schorderet-Slatkine, 1983), hamster (C. Racowsky, unpublished) and pig (C. Racowsky, unpublished) oocytes. The lack of forskolindependent arrest of denuded rat oocytes reported here cannot be accounted for by a reduction, during preparation of the oocytes for culture, in the intra-oocyte cAMP level below the threshold required to maintain meiotic arrest. Although no phosphodiesterase inhibitor was used in the collection medium, the time for collection and denudation of oocytes was $5.5 \pm 0.3 \mathrm{~min}$, a period in which only about $5 \%$ of oocytes have been shown to undergo irreversible commitment to spontaneous maturation (Dekel \& Beers, 1980). Since the timing for reinitiation of meiosis in mouse and rat oocytes is similar, it is possible that there is a marked difference between these species with respect to the presence of adenylate cyclase in the oolemma. Consistent with this possibility are the observations, derived from experiments with choleratoxin, that, in contrast to sheep (Moor \& Heslop, 1981), mouse (Schultz et al., 1983b; Vivarelli et al., 1983) and pig (C. Racowsky, unpublished) oocytes, rat oocytes appear not to possess a regulatory subunit of adenylate cyclase (Dekel \& Beers, 1980). An alternative explanation for the difference in response of rat oocytes to adenylate cyclase stimulators may relate to the extent to which cumulus cell processes remain within the zona pellucida of different species after mechanical denudation. If this is the case, it is possible that adenylate cyclase on cumulus cell membranes remaining within the zona could account for the varied responses of 'denuded' oocytes of several species to adenylate cyclase stimulators. This possibility is currently being investigated.

The observation that the cAMP content of cumulus-enclosed oocytes was elevated compared with that of denuded oocytes at all concentrations of forskolin tested (Text-fig. 2) is consistent with transfer of cAMP, derived from the cumulus, into the oocyte. This conclusion is supported by the highly significant correlation established between the content of CAMP within a group of cumulus masses and that in the corresponding group of enclosed oocytes $(r=0.78, P<0.001)$, but is in direct contrast to the conclusion of Schultz et al. (1983b). In this earlier study, no increase in intraoocyte cAMP was observed in choleratoxin $(2 \mu \mathrm{g} / \mathrm{ml})-$ or FSH $(2 \mu \mathrm{g} / \mathrm{ml})$-stimulated cumulusenclosed oocytes as compared with denuded oocytes of mice. These data led to the conclusion that mammalian cumulus cell cAMP is compartmentalized and not transferred to the oocyte. It is possible that the limited experimental conditions of Schultz et al. (1983b) did not allow for demonstration of cumulus cell cAMP transfer. In support of the latter, is the present finding that low concentrations of forskolin (up to $0.782 \mu \mathrm{M}$ ) induced a relatively slight increase in intra-oocyte cAMP content of cumulus-enclosed oocytes but that higher doses of the drug stimulated marked transfer (Text-fig. 2). Further support for the general concept that cumulus cell cAMP is transferred to the mammalian oocyte is given by the findings that the cAMP content of hamster and pig 
cumulus-enclosed oocytes is also elevated by forskolin above that of denuded oocytes at all concentrations of drug tested (C. Racowsky, unpublished). The possibility nevertheless exists that, in the cumulus-enclosed oocyte, forskolin stimulates the cumulus cells to promote oocyte adenylate cyclase activity when functional metabolic coupling is maintained.

Forskolin-dependent maintenance of meiotic arrest of intact oocytes was reversible (Table 2) and the arresting action was transient (Table 3). These observations are consistent with the action of forskolin upon meiosis of cumulus-enclosed hamster oocytes (C. Racowsky, unpublished), and support the previous conclusion, obtained from work with many cell systems, that forskolin stimulation of adenylate cyclase is reversible (Seamon \& Daly, 1981; Seamon et al., 1981). While this study has not established the basis for the transitory arresting action of forskolin, the finding that intra-oocyte cAMP dropped precipitously and concomitantly with release from transient arrest maintained by $25 \mu \mathrm{M}$-forskolin at $8 \mathrm{~h}$ of culture (Table 4 ) suggests that a decrease in intraoocyte cAMP may be involved in this process. This conclusion is supported by the observation that there is a significant fall in the cyclic nucleotide content of rat oocytes after the first hour of removal from the follicle (C. Racowsky, unpublished), when $82 \%$ of cumulus-enclosed rat oocytes are irreversibly committed to maturation (Dekel \& Beers, 1980). There are at least two possible explanations to account for the observed reduction in intra-oocyte cAMP at $8 \mathrm{~h}$ of culture in $25 \mu \mathrm{M}$ forskolin. Firstly, transfer of cumulus cell cAMP into the oocyte may have decreased with culture time. This possibility is supported by the observation that the cAMP content of cumulus cells remained unchanged between 4 and 8 h of culture (Table 4), but heterologous metabolic coupling progressively declined (Table 3). Alternatively, oocyte phosphodiesterase activity may have increased with culture time. That the mammalian oocyte possesses a phosphodiesterase is supported by the numerous reports that phosphodiesterase inhibitors prevent resumption of meiosis (Cho et al., 1974; Magnusson \& Hillensjö, 1977; Dekel et al., 1981; Vivarelli et al., 1983) and the observation that MIX elevates the cAMP content of cultured mouse oocytes (Vivarelli $i t$ al., 1983).

On the basis of the present findings it is concluded that (1) the rat oolemma does not possess sufficient functional subunits of adenylate cyclase to catalyse conversion of ATP to cAMP in an amount adequate to maintain meiotic arrest, and (2) the cumulus cells maintain meiotic arrest in rat oocytes by transfer of cAMP into the oocyte. Furthermore, the results suggest that a decrease in the content of oocyte cAMP triggers the resumption of meiosis in the rat. While the present data for the rat oocyte are consistent with the hypothesis of Dekel \& Beers $(1978,1980)$ for the regulation of mammalian meiotic maturation, they differ in one or more respects from those reported for all other mammalian oocytes so far studied. The possibility exists, therefore, that different mechanisms operate in different mammalian species to regulate oocyte meiosis.

I thank Robin Hendricks and Mark Pasch for excellent technical assistance, Nancy Meffe for typing the manuscript; Larry Nienaber for breeding the rats; and Dr R. W. McGaughey for discussion. This study was supported by Grants No. HD15984 and HD16788 from the NIH.

\section{References}

Anderson, E. \& Albertini, D.F. (1976) Gap junctions between the oocyte and the companion follicle cells in the mammalian ovary. $J$. Cell Biol. 71, 680686.

Brinster, R.L. (1971) Measuring embryonic enzyme activities. In Methods in Mammalian Embryology, pp. 215-227. Ed. J. C. Daniel, Jr. W. H. Freeman and Co., San Francisco.

Cho, W.K., Stem, S. \& Biggers, J.D. (1974) Inhibitory effect of dibutyryl cAMP on mouse oocyte maturation in vitro. J. exp. Zool. 187, 383-386.
Dekel, N. \& Beers, W.H. (1978) Rat oocyte maturation in vitro: relief of cyclic AMP inhibition by gonadotropins. Proc. natn. Acad. Sci. U.S.A. 75, 4369-4373.

Dekel, N. \& Beers, W.H. (1980) Development of the rat oocyte in vitro: inhibition and induction of maturation in the presence or absence of the cumulus oophorus. Devl Biol. 75, 247-254.

Dekel, N., Lawrence, T.S., Gilula, N.B. \& Beers, W.H. (1981) Modulation of cell to cell communication in the cumulus-oocyte complex and the regulation of oocyte maturation by LH. Devl Biol. 86, 356-362. 
Duncan, D.B. (1955) Multiple range and multiple ' $F$ ' tests. Biometrics II, 1-42.

Eppig, J.J. (1982) The relationship between cumulus celloocyte coupling, oocyte meiotic maturation and cumulus expansion. Devl Biol. 89, 268-272.

Gilula, N.B., Epstein, M.L. \& Beers, W.H. (1978) Cell-tocell communication and ovulation: a study of the cumulus-oocyte complex. J. Cell Biol. 78, 58-75.

Harper, J.F. \& Brooker, G. (1975) Femtomole sensitive radioimmunoassay for cyclic AMP and cyclic GMP after 2' O-acetylation by acetic anhydride in aqueous solution. J. cyc. Nucleotide Res. 1, 207-218.

Heller, D.T. \& Schultz, R.M. (1980) Ribonucleoside metabolism in mouse oocytes: metabolic cooperativity between the fully-grown oocyte and cumulus cells. J. exp. Zool. 214, 355-364.

Hillensjö, T., Hamberger, L. \& Ahren, K. (1975) Respiratory activity of oocytes isolated from ovarian follicles of the rat. Acta endocr., Copenh. 78, 751-759.

Magnusson, C. \& Hillensjö, T. (1977) Inhibition of maturation and metabolism in rat oocytes by cyclic AMP. J. exp. Zool. 201, 139-147.

McGaughey, R.W. (1977) The culture of pig oocytes in minimal medium, and the influence of progesterone and estradiol-17 $\beta$ on meiotic maturation. Endocrinology 100, 39-45.

McGaughey, R.W. (1978) In vitro oocyte maturation. In Methods in Mammalian Reproduction, pp. 1-20. Ed. J. C. Daniel, Jr. Academic Press, New York.

McGaughey, R.W. \& Polge, C. (1971) Cytogenetic analysis of pig oocytes matured in vitro. J. exp. Zool. 176, 383-391.

McGaughey, R.W. \& Van Blerkom, J. (1977) Patterns of polypeptide synthesis of porcine oocytes during maturation. Devl Biol. 56, 241-254.

Moor, R.M. \& Heslop, J.B. (1981) cAMP in mammalian follicle cells and oocytes during maturation. J. exp. Zool. 216, 205-209.

Moor, R.M., Smith, M.W. \& Dawson, R.M.C. (1980) Measurement of intercellular coupling between oocytes and cumulus cells using intracellular markers. Expl Cell Res. 126, 15-29.

Mulner, O., Cartaud, A. \& Ozon, R. (1980) Cyclic AMP phosphodiesterase activities in Xenopus laevis oocytes. Differentiation 16, 31-39.

Nie, N., Hull, C., Jenkins, J., Steinbrenner, K. \& Brent, D. (1975) Statistical Package for the Social Sciences, 2nd edn, p. 422. McGraw-Hill, New York.
Racowsky, C. (1983) Androgenic modulation of cyclic adenosine monophosphate (cAMP)-dependent meiotic arrest. Biol. Reprod. 28, 774-787.

Rice, C. \& McGaughey, R.W. (1981) Effect of testosterone and dibutyryl cAMP on the spontaneous maturation of pig oocytes. J. Reprod. Fert. 62, 245-256.

Schultz, R.M., Montgomery, R.R. \& Belanoff, J.R. (1983a) Regulation of mouse oocyte meiotic maturation: implication of a decrease in oocyte cAMP and protein dephosphorylation in commitment to resume meiosis. Devl Biol. 97, 264-273.

Schultz, R.M., Montgomery, R.R., Ward-Bailey, P. \& Eppig, J.J. (1983b) Regulation of ocyte maturation in the mouse : possible roles of intercellular communication, cAMP and testosterone. Devl Biol. 95, 294304.

Seamon, K.B. \& Daly, J.W. (1981) Forskolin: a unique diterpene activator of cyclic AMP generating systems. J. cyc. Nucleotide Res. 7, 201-224.

Seamon, K.B., Padgett, W. \& Daly, J.W. (1981) Forskolin: a unique diterpene activator of adenylate cyclase in membranes and in intact cells. Proc. natn. Acad. Sci. U.S.A. 78, 3363-3367.

Szöllösi, D. (1975) Ultrastructural aspects of oocyte maturation and fertilization in mammals. In $L a$ Fecondation, pp. 13-35. Ed. C. Thibault. Masson, Paris.

Tsafriri, A. \& Channing, C.P. (1975) An inhibitory influence of granulosa cells and follicular fluid upon porcine oocyte meiosis in vitro. Endocrinology 96,922 927.

Urner, F., Herrmann, W.L., Baulieu, E.-E. \& SchorderetSlatkine, S. (1983) Inhibition of denuded mouse oocyte meiotic maturation by forskolin, an activator of adenylate cyclase. Endocrinology 113, 1170-1172.

Vivarelli, E., Conti, M., De Felici, M. \& Siracusa, G. (1983) Meiotic resumption and intracellular cAMP levels in mouse oocytes treated with compounds which act on cAMP metabolism. Cell Differentiation 12, 271-276.

Wang, C.H., Willis, D.L. \& Loveland, W.D. (1975) In Radiotracer Methodology in the Biological, Environmental and Physical Sciences, pp. 221-224. PrenticeHall, Inc., Englewood Cliffs.

Warme, P.K. (1980) Curve Fitter Program. Interactive Microware, Inc., P. O. Box 771, State College, PA 1680 .

Received 13 January 1984 